been taking ten-grain doses for three weeks only at the time when the symptom was reported.

Since the cases above referred to, together with the two recorded in this paper, appear to establish the fact that iodoform is liable to cause amblyopia, it becomes a question whether its use internally is any longer justifiable. This question may, I think, be answered in the affirmative, always supposing that the treatment is of real value. In my own cases and in that recorded by Hirschberg, recovery was complete and rapid after the discontinuance of the iodoform; in the other two recovery was progressing satisfactorily when the last notes were taken. It therefore seems probable that if the amblyopia be early recognised and the drug promptly omitted no permanent mischief need be feared. I have now adopted the plan of recording the vision of all those patients whom I am about to treat with iodoform before beginning its administration; I then make periodical inquiries as to the sight, and am able to discover when any diminution is acknowledged whether alteration has really taken place. This measure is, I find, absolutely necessary owing to the certainty in hospital out-patient practice that any symptom frequently inquired for will sooner or later be acknowledged by the patient. I have only to add that in my cases the onset of the amblyopia was not accompanied by any other symptom.

Birmingham.

\section{FOUR SUCCESSFUL CASES OF TRANS- FUSION OF SALINE FLUID.}

By NATHAN RAW, M.D. DURH., \&C.,

MEDICAL SUPERINTENDENT AND PATHOLOGIST, DUNDEE ROYAT. INEIRMARY.

In The LANCeT of Aug. 17th, 1895, I recorded six successful cases of transfusion of normal saline solution, and since that time several cases have occurred in the practice of whe Dundee Royal Infirmary in which transfusion has been employed, in some with wonderful effect and in others with well-marked temporary improvement. The following is a brief note of the successful cases.

CASE 1.-A woman, aged thirty-nine years, pashed her arm through a window, severely lacerating it. She bled profusely and on admission to the infirmary an hour afterwards was in a very serious condition. She was quite unconscious and markedly anæmic; the respiration was shallow, with occasional sighing; no pulse could be -detected. She had a transverse wound over the front of the left elbow-joint severing the radial artery at its origin. The median cepbalic vein was also divided, and into this were transfused five pints of normal saline solution at a temperature of $105^{\circ} \mathrm{F}$. The effect was very wonderful. In a few minutes she opened her eyes, consciousness slowly returned, and the pulse became quite good and regular. She made a good recovery and went home in ten days.

CASE 2.-A boy, aged twelve years, was admitied to the infirmary on March 25th, 1896, under the care of Dr. MacE wan, with extensive disease of the right knee-joint. He was in a fairly healthy condition. Dr. MacE wan excised the right knee-joint, and numerous tuberculous deposits were found in the femur and tibia, even above the epiphyseal lines. The medullary cavity of the femur was opened and drained. The patient did not suffer from shock or loss of blood, and he bore the operation well. He remained fairly well for thirtysix hours, when he suddenly developed a rigor and became delirious; his temperature was $103^{\circ} \mathrm{F}$. and his pulse 144 . The wound was dressed but found to be sweet. Eight hours afterwards he was quite unconscious and apparently dying. The left internal saphenous vein was opened, and four pints of saline fluid were introduced with a very good effect, as, with the exception of a severe rigor half an hour after the injection, he made a good recovery and is now almost well.

CASE 3.-A man, aged thirty-two years, had his arm caught in machinery, rupturing the brachial artery and smashing the arm. He lost a very large amount of blood and when brought to the hospital was in a very collapsed state. Amputation at the shoulder-joint was performed. He suffered from collapse, and during the night his pulse could not be felt. He was transfused with five pints of saline fluid. An hour afterwards he had a rigor, with a temperature of $103^{\circ} \mathrm{F}$, but with this exception he made a rapid recovery.

CASE 4 -A woman, aged twenty-three years, was admitted on June 6th, 1896, under the care of Dr. Whyte, suffering from purpura and anæmia. She had several severe attacks of violent epistaxis which were difficult to control. The patient's condition became very serious; the pulse was quite imperceptible, and she was apparently dying. She was transfused with five pints of saline solution, with the effect noticed in Cases 2 and $5-v i z .$, a rigor and temperature of $104^{\circ} \mathrm{F}$. one hour later. She revived almost at once and made an excellent recovery.

Remarks.--There can be no doubt that we have in transfusion one of the most simple yet efficacious remedies in all cases of shock from hæmorrhage. How far it is of service in cases of nervous shock and collapse is yet undecided, but in some cases it is of great value. Larger quantities should be given than those generally recommended, four or five pints being a usual quantity. I have given as much as twenty-four pints at four injections within twenty-four hours without any apparent discomfort. I have noticed in several cases the occurrence of a rigor, commencing from half an hour to an hour after the operation and lasting about five minutes, with a high temperature. This seems to have no serious effect, the temperature quickly subsides, and recovery is not retarded by it. In Case 2 there is every reason to suppose that an acute attack of septic osteo-myelitis was cut short by the transfusion, my explanation being that an increased volume in the vessels would offer a greater resistance to attack and at the same time dilute the blood stream and so disperse the micro-organisms. If this be so, there is reason to suppose that transfusion may be employed in acute specific diseases due to micro-organisms, as in any case it could have no other than a highly beneficial effect if performed with ordinary care and with a sterilised solution. The apparatus I use consists of an ordinary glass funnel and tubing, with a glass nozzle for insertion into the vein.

Dundee.

\section{NOTES ON THE ANATOMY, DEVELOPMENT, PATHOLOGY, AND SURGERY OF THE FRONTAI SINUSES.}

By MAYO COLLIER, M. S. LOND., F.R.C.S. ENG., SENIOR ASSISTANT SURGEON TO THR NORTH-WEST LONDON HOSPITAX.

Anatomy.-The frontal sinuses are generally two irregular cavities between the inner and outer tables of the frontal bone, near the root of the nose. In the fresh state these cavities are lined with a thin, pale, closely-adherent mucous membrane, and separated from each other by a well-marked septum. They usually communicate separately with the corresponding nasal cavity by an opening, variable in size, leading into the anterior extremity of the middle meatus of the nose. The examination of a large number of frontal sinuses in the moist and dry state discloses many points of interest. In the first place there is no space between the tables of the frontal bone before the seventh year. There may be a complete absence of these cavities even in extreme old age. I have bones in my possession showing a frontal sinus only on one side. The extent of the frontal sinuses varies widely, and unfortunately the external appearances of the skull give no indication of these variations. The frontal sinuses are seldom symmetrical, except in a general sense. Of the extent of these spices there are specimens in the Museum of the Royal College of Surgeons of England, showing a separation of the inner and outer tables of the frontal bone almost to the coronal suture. The orbital plate of the frontal bone is frequently the site of a large cavity communicating with, and forming part of, the frontal sinuses. The frontal sinus of one side may not communicate with the nose or its fellow of the opposite side, but may communicate with the anterior ethmoidal cells of the same side. The septum dividing the two sinuses is usually partly bony and partly fibrous, but is always well marked. It may be entirely bony or entirely fibrous. Its central position is constant. I have never found a frontal sinus not in communication, directly or indirectly, with the nose. The evolution of the frontal sinuses is not complete until the twenty-first year. 